\title{
Cross-cultural validation of the Functional Vision Questionnaire for Children and Young People (FVQ_CYP) with visual impairment in the Dutch population: challenges and opportunities
}

Ellen B. M. Elsman ${ }^{1 *+}$ (D), Valerija Tadić ${ }^{2,3,4+}$, Carel F. W. Peeters ${ }^{5}$, Ger H. M. B. van Rens ${ }^{1,6}$, Jugnoo S. Rahi ${ }^{3,4,7,8+}$ (1) and Ruth M. A. van Nispen ${ }^{1+}(\mathbb{D}$

\begin{abstract}
Background: To assess cross-cultural validity between Dutch and English versions of the FVQ_CYP, a patientreported outcome measure developed in the United Kingdom (UK) for children and adolescents with (severe) visual impairment or blindness (VI for brevity) to measure functional vision.

Methods: The 36-item FVQ_CYP was translated and adapted into Dutch using standard guidelines. The questionnaire was administered to Dutch children and adolescents aged 7-17 years $(N=253)$ with impaired vision (no restrictions regarding acuity). Data were compared to existing UK data of children and adolescents aged 10-15 years $(N=91)$ with VI (acuity LogMar worse than 0.48). As with the original UK FVQ_CYP validation, a rating scale model (RSM) was applied to the Dutch data.
\end{abstract}

Results: Minor adaptations were needed in translation-rounds. Significant differences in item responses were found between the Dutch and UK data. Item response theory assumptions were met, but fit to the RSM was unsatisfactory. Therefore, psychometric properties of the Dutch FVQ_CYP were analysed irrespective of the original model and criteria used. A graded response model led to the removal of 12 items due to missing data, low information, overlapping content and limited relevance to Dutch children. Fit indices for the remaining 24 items were adequate.

Conclusions: Differences in population characteristics, distribution of responses, non-invariance at the model level and small sample sizes challenged the cross-cultural validation process. However, the Dutch adapted FVQ_CYP showed high measurement precision and broad coverage of items measuring children's functional vision. The underlying reasons for differences between countries in instrument performance are discussed with implications for future studies.

Keywords: Visual impairment, Cross-cultural validation, Children, Functional vision, Item response theory, Differential item functioning

\footnotetext{
* Correspondence: e.elsman@amsterdamumc.nl

'Ellen B. M. Elsman and Valerija Tadić contributed equally to this work. Jugnoo S. Rahi and Ruth M. A. van Nispen also contributed equally to this work.

'Department of Ophthalmology, Amsterdam UMC, Vrije Universiteit

Amsterdam, the Amsterdam Public Health research institute, Amsterdam, the

Netherlands

Full list of author information is available at the end of the article
}

(c) The Author(s). 2019 Open Access This article is distributed under the terms of the Creative Commons Attribution 4.0 International License (http://creativecommons.org/licenses/by/4.0/), which permits unrestricted use, distribution, and reproduction in any medium, provided you give appropriate credit to the original author(s) and the source, provide a link to the Creative Commons license, and indicate if changes were made. The Creative Commons Public Domain Dedication waiver (http://creativecommons.org/publicdomain/zero/1.0/) applies to the data made available in this article, unless otherwise stated. 


\section{Background}

In recent years, emphasis on patient-centred care has resulted in the development of generic and disease-specific patient-reported outcome measures (PROMs) [1, 2]. Using PROMs, health outcomes such as quality of life, functional status and disease severity, which are preferably reported by patients themselves, can be assessed and monitored [3-5]. Although many vision-specific instruments for adult populations exist (e.g. [6-12]), there is a paucity of such measures in paediatric ophthalmology.

Availability and implementation of instruments to assess functional vision in paediatric ophthalmology would complement objective clinical measures of visual function, such as visual acuity and visual field. Furthermore, these instruments can be used to monitor and evaluate the effectiveness of low vision rehabilitation. Currently, three measures of functional vision are available. Both of the two versions of the LV Prasad-Functional Vision Questionnaire have been developed for children in the developing world [13, 14], and therefore some items have limited applicability in developed countries. The Cardiff Visual Ability Questionnaire for Children and Young People has been developed and tested in a specific geographical area in the United Kingdom (UK), and although translated and validated in Turkish and Chinese $[15,16]$, its applicability elsewhere is currently limited [17].

The Functional Vision Questionnaire for Children and Young People (FVQ_CYP) for 10 to 15 year olds was previously designed to capture self-reported level of difficulty in the performance of vision dependent activities and is intended for children and adolescents with visual impairment (VI), severe VI or blindness i.e. with acuity in their better seeing eye of $\log M A R$ worse than 0.48 . It was developed for and validated in a nationally representative sample of UK children [18]. The FVQ_CYP 1015 years comprises 36 items measured on a 4-point scale. It has good psychometric properties, and is relatively short and easy to complete. Previous analyses, including Rasch analysis, have demonstrated its unidimensionality, reliability and robustness [18]. Extensions of the FVQ_CYP to cover the age range 8 to 18 years are currently in development.

No measure of functional vision is currently available in the Netherlands. Although progress is being made in the development of age-specific versions of the Participation and Activity Inventory for Children and Youth (PAI-CY) [19], there is a need for a reliable and valid measure of functional vision for children and adolescents. Such instrument can be used as a PROM, complimentary to the objective clinical measures of visual function in ophthalmology, as an outcome instrument in research evaluating therapies of interventions, or to monitor and assess the effectiveness of low vision rehabilitation. The aim of this study was to translate the FVQ_CYP in Dutch, including assessment of its crosscultural validity using Item Response Theory (IRT) analysis. Data for this study was collected as part of a study in which the PAI-CY was developed and its psychometric properties were assessed. The study was performed among a population of children aged 7-17 years with impaired vision from any cause who were registered at a low vision service for a functional vision assessment or various other rehabilitation or early interventions.

\section{Methods}

The cross-cultural validation of the FVQ_CYP was conducted in two phases. The first phase consisted of translation of the FVQ_CYP into Dutch, in keeping with standardized guidelines [20]. The second phase entailed the assessment of psychometric properties of the Dutch version of the FVQ_CYP (FVQ_CYP_NL) using IRT analysis that drew on the existing anonymised UK dataset for the FVQ-CYP.

\section{Phase 1: translation of the FVQ_CYP into Dutch}

The FVQ-CYP was translated in Dutch using an established process for cross-cultural adaptation of PROMs [20]. It comprised five stages outlined below:

\section{Initial forward translations}

Forward translation from English (source language) into Dutch (target language) was carried out by two independent bilingual translators, having Dutch as native language but were also fluent in English. Both translators were researchers regularly working with visually impaired children and aware of the concept of functional vision, and were as such informed translators. The instructions, questionnaire items, and scale were translated independently without any discussion between the translators.

\section{Synthesis of the translations}

The two translations were compared and any discrepancies were resolved through discussion and/or consultation of a third researcher not involved in the forward translation. Working from the original FVQ_CYP, as well as from the two translations, a synthesis of these translations was produced, resulting in one common translation.

\section{Back translations}

The translated version of the FVQ_CYP was then translated back to English by two bilingual translators who were native English speakers. The two back-translators were naive to the original English version of the FVQ CYP and lay to the concept of functional vision and VI. 


\section{Expert committee review}

An expert committee including the project leader and all four translators reviewed all translations and resolved discrepancies through discussion resulting in consensus on the final wording to be used for the final version of the Dutch FVQ_CYP (FVQ_CYP_NL).

\section{Phase 2: assessing psychometric properties of the FVQ_CYP_NL \\ Study design and participants}

Children and adolescents aged 7-17 years enrolled for care at two Dutch low vision rehabilitation centres at the time of the study or in the past were invited to participate in the study. Children were required to have adequate knowledge and understanding of the Dutch language to participate in the study. Children with registered extensive (cognitive) impairment were excluded from the sample to be invited to participate by the low vision rehabilitation centres. Children with low vision from any cause were eligible and there was no restriction regarding visual acuity. As such, the inclusion criteria were more liberal with respect to both age and visual acuity than for the original instrument development and validation in the UK, which was intentionally limited to children and adolescents aged 10-15 years old with VI/ severe VI or blindness i.e. visual acuity in the better eye of $\log$ MAR $\geq 0.48$ [18]. More details of the UK sample have been published elsewhere [18]. All eligible Dutch children and their parents were sent a letter explaining the aim and procedure of the study and appropriate consent forms asking whether they would agree to participate. Parents of children who did not respond were telephoned to provide further information about the study and ask for their reasons for declining participation.

Although the original FVQ_CYP is intended for selfadministration, Dutch children and adolescents who participated in the study were visited at their home by a researcher in order to administer the FVQ_CYP_NL using an interview format, providing an extra check on ability to participate. Besides, using an interview format was in line with the mode of administration applied for testing the PAI-CY. Parents provided information on socio-demographic and clinical characteristics of their child, such as age, gender, siblings, cause of low vision, level of VI, and other impairments, using a web-based survey questionnaire. Decimal visual acuity, visual field and ophthalmic diagnoses were retrieved from patient files at the low vision rehabilitation organisations. Missing values in patient files were supplemented by selfreported data of parents $(n=8)$. Visual acuity was converted into $\log \mathrm{MAR}$, and put into 5 levels based on the better seeing eye, according to World Health Organisation (WHO) taxonomy of VI [21]. VI0 referred to logMAR $\leq 0.47$, VI1 to $\operatorname{logMAR} 0.48-0.70$, VI2 to $\log$ MAR
0.71-1.00, SVI to logMAR 1.01-1.30, and blind to logMAR $\geq 1.31$. Thus VI0 was not a category/population for which the FVQ_CYP was designed. When data on visual field was available, visual field of $\leq 10$ degrees was classified as blind; otherwise only visual acuity was used for classification.

The study protocol was approved by the Medical Ethical Committee of the Amsterdam UMC, location VUmc, the Netherlands. The study adhered to the tenets of the Declaration of Helsinki and its later amendments. Written informed consent was obtained from all Dutch participants, i.e. from parents of all children, and from children and adolescents aged 13 years and older. Secondary analysis of the existing anonymised UK FVQ CYP dataset did not require ethics approval. The data were drawn from the original development and psychometric study which involved individual consent to participation and was approved by the National Health Service Research Ethics Committee for UCL Institute of Child Health and Great Ormond Street Hospital, United Kingdom, and followed the tenets of the Declaration of Helsinki.

\section{Statistical analysis}

All statistical analyses related to IRT were conducted in $\mathrm{R}$ [22]. The remaining analyses were completed using SPSS version 22 [23].

Participants with $>25 \%$ missing responses were removed from the analyses. Sociodemographic and clinical characteristics for the Dutch and UK sample were investigated separately.

Item analysis, comprising descriptive statistics of each of the individual items, were conducted for the Dutch and UK samples. Differences in the distribution of responses over the response categories were investigated using chi-square tests.

Following the cut-off criteria used in the validation of the original FVQ_CYP [18], items in the Dutch sample with $>20 \%$ missing data were flagged. Moreover, items with $>60 \%$ of the responders endorsing the first or last response category (floor and ceiling effect) were flagged, as were items showing certain response categories to be redundant (i.e. not having an answer in a certain response category). Inter-item correlations were evaluated and item-pairs were flagged when correlations were > 0.7 , indicating potential redundancy.

Then, IRT was applied on the Dutch sample. IRT comprises a collection of modelling techniques from modern measurement theory. It provides a powerful context to develop instruments which are more efficient, reliable and valid [24]. The statistical models used in IRT analyses describe the association between a person's ability (latent trait, e.g. disability, denoted as theta $(\theta)$ ) and the probability of that person choosing a certain 
response option of an item in a multi-item scale measuring that trait [25]. Application of IRT models requires three assumptions:

- Unidimensionality, which assumes that a single latent trait explains the covariance of items [24]. Unidimensionality was assessed by performing an eigen value decomposition on the matrix of robust (Spearman) correlations between the items. A difference approximation to the second-order derivatives along the eigenvalue curve (scree plot) was calculated. This acceleration-approximation indicates points of abrupt change along the eigenvalue curve and the number of eigenvalues before the point with the most abrupt change (the point with the maximum acceleration value) represents the number of latent dimensions that dominate the information content [26]. Subsequently a principal component analyses (PCA) was performed to proxy if all items load on a single component (where the component is taken as a proxy for the latent trait).

- Local independence of items, which requires that item responses are independent given their relationship to the latent trait. Local dependence was assessed by inspection of possible excess covariation $(>0.25)$ among items in the residual matrix resulting from PCA. Local dependence could occur in items that are similar in content, refer to a similar condition (similar stem) or are presented successively [24]. Item pairs with excess covariation were flagged.

- Monotonicity, which states that the probability of endorsing a higher item response category should not decrease with increasing levels of the underlying latent trait [27]. Monotonicity was evaluated using Mokken scale analysis. The graphs were visually inspected, and the Loevinger $\mathrm{H}$ coefficient was calculated to assess scalability [28] (see also [29, 30]).

A Loevinger $\mathrm{H}$ coefficient $<0.30$ was considered unsatisfactory.

Because on the original FVQ_CYP the rating scale model (RSM) was used [18], this model was also applied to the Dutch data using the eRm package [31]. However, the goodness-of-fit test was not suggestive for satisfactory model fit of the RSM to the Dutch data. Moreover, item misfit was indicated by multiple tests (i.e. graphical model check, Wald test and chi-square fit statistics). Therefore, it was decided to apply another IRT model to the data of the FVQ_CYP_NL. The graded response model (GRM) was selected for this purpose, as it is one of the most commonly used IRT models to evaluate questionnaires with ordinal response categories. It estimates a discrimination parameter $(\alpha)$ and threshold parameters $(\beta)[32,33]$. The thresholds mark the points on the latent trait where the probability of endorsing the response category of an item is $50 \%$, whereas the discrimination specifies the slope of the item curves; the discrimination describes the ability of an item to differentiate between individuals with different trait levels. Using the ltm package [34], model fit of the GRM was assessed by comparing a full model [24] with a constrained model [24, 35], which is nested within the full model and has equal discrimination parameters across all items (analogous to the Rasch model). A Likelihood Ratio test was performed to assess whether the full model fitted the data better than the constrained model. Overall fit of the selected model was assessed using the mirt package [36], yielding several fit indices: root mean square error of approximation (RMSEA), standardized root mean square residual (SRMR), comparative fit index (CFI), and Tucker-Lewis index (TLI). The CFI and TLI should be around 0.95 or higher, whereas the SRMR should be around 0.08 or lower and the RMSEA around 0.06 or lower [37].

Some items might not fit the GRM model, and therefore individual item fit was assessed using the $\mathrm{X}^{2}$ statistic [38, 39]. Significance of this test was adjusted for the number of items to correct for multiple testing. Then item information of an item over the latent trait was examined to assess item functioning. Item information refers to the information content of an item in relation to the total test information, and therefore represents reliability or measurement precision [24]. Items with low information across the disability trait were considered for elimination, but the Item Information Curves (IICs) and Category Response Curves (CRCs) also informed decisions, as did content validity. The IICs show the range of the underlying trait over which an item is most useful to distinguish between participants. The CRCs show the relation between the latent trait and the probability of responding to a categorical item [40]. When the curves of two or more items cover the same area on the disability trait, the item with least information and/or holding information over the smallest range of the disability trait was considered for elimination. A person-item map was computed with the WrightMap package to evaluate whether item difficulty matches participants' ability [41]. It shows the distribution of person parameters (thetas of respondents) on the left side of the map and the distribution of item parameters (thresholds) on the right side.

Differential item functioning (DIF) analyses were used to assess whether participants from different groups (i.e. age and gender) with the same level of disability have different probabilities of selecting a certain response to an item $[40,42]$. Two certain types of DIF can be distinguished. Uniform DIF means that an item is endorsed either more or less often at all values of the latent trait 
by one group compared to the other. Non-uniform DIF does not occur equally at all points on the latent trait, i.e. an item is endorsed either more or less often at some values and the other way around at other values by one group compared to the other [42]. DIF was assessed with the lordif package [43], using an iterative hybrid of ordinal logistic regression and IRT. The likelihood ratio $x^{2}$ test at $\alpha$ level 0.01 was used as detection criterion, and McFadden's pseudo $\mathrm{R}^{2}$ was used as a measure of magnitude of DIF; a change of $2 \%$ was considered as critical value [44]. DIF was evaluated for age (median split: younger than 11 years vs. 11 years and older) and gender (male vs. female).

Known-group validity was assessed to ensure the FVQ_CYP_NL is able to discriminate between groups [42]. Therefore, differences in thetas between groups that differed in level of VI, other impairments and gender were assessed using independent samples t-tests and ANOVA with post hoc Tukey test. VIO formed the group mild VI, VI1 and VI2 were combined in the group moderate VI, and SVI and blind were combined in the group severe VI/blindness. Participants with unknown levels of vision impairment were excluded from this analysis. It was expected that thetas would increase for increasing levels of VI (signalling worse functional vision), females would have similar thetas as males, and those with other impairments would have higher thetas than those without other impairments.

\section{Results}

\section{Translation of the FVQ CYP into Dutch}

Some minor differences in wording of two items related to activities at school, i.e. "taking part in science classes" and "seeing the board in the class" were found and were resolved by discussion: examples (i.e. physics and biology) were added to science classes, and board was translated to schoolboard or digital board, as most schools in the Netherlands nowadays use a digital board. During the first questionnaire administration to participants, it was noted that the response option 'not applicable' was warranted, because in the Netherlands young children usually do not have homework for which they need the computer, and not all classes (e.g. science and geography) are obligatory for all ages to which the questionnaire was administered. It is worth noting that the 'not applicable' option was also included in the original FVQ_CYP UK study, but was subsequently removed due to high endorsement of this category, resulting in a high proportion of 'missing' data. Furthermore, it was noted that different wording might be necessary for younger children vs. the older children. For example, math classes were translated into the Dutch word "wiskunde" (i.e. mathematics), but only children in high school have "wiskunde". In primary school, this class is called "rekenen" (i.e. to calculate). Therefore, two ageappropriate versions (7-12 years and 13-17 years respectively) of the FVQ_CYP_NL were created with minor differences in the wording of five items related to activities at school.

\section{Participant characteristics}

A total of 263 Dutch children and adolescents were recruited in this study. Ten participants were excluded from the analyses because they had an excessive number of missing responses. In the UK dataset, this was the case for three participants, resulting in a dataset containing responses of 91 children and adolescents. The demographic and clinical characteristics of the Dutch sample and the UK sample are summarised in Table 1. As expected there were differences in age, level of VI and occurrence of other impairments, due to more liberal

Table 1 Socio-demographic and clinical characteristics of the Dutch and the UK sample

\begin{tabular}{|c|c|c|}
\hline & $\begin{array}{l}\text { Dutch sample } \\
N=253\end{array}$ & $\begin{array}{l}\text { UK sample } \\
N=91\end{array}$ \\
\hline Age in years, mean $\pm S D$ (range) & $11.06 \pm 2.87(7-18)$ & $12.09 \pm 1.84(9-15)$ \\
\hline \multicolumn{3}{|l|}{ Gender, n (\%) } \\
\hline Male & $150(59.3)$ & $52(57.1)$ \\
\hline Female & $103(40.7)$ & $39(42.9)$ \\
\hline \multicolumn{3}{|l|}{ Level of VI } \\
\hline VIO: $\log M A R \leq 0.47$ & $126(49.8)$ & - \\
\hline VI1: logMAR 0.48-0.70 & $56(22.1)$ & $42(46.2)$ \\
\hline VI2: logMAR 0.71-1.00 & $35(13.8)$ & $31(34.1)$ \\
\hline SVI: logMAR 1.01-1.30 & $4(1.6)$ & $10(11.0)$ \\
\hline Blind: $\log M A R \geq 1.31$ & $24(9.5)$ & $8(8.8)$ \\
\hline Unknown & $8(3.2)$ & - \\
\hline \multicolumn{3}{|l|}{ Nationality } \\
\hline Ethnic majority & $228(90.1)$ & 77 (84.6) \\
\hline Ethnic minortiy & $25(9.9)$ & $14(15.4)$ \\
\hline \multicolumn{3}{|l|}{ Other impairment, n (\%) } \\
\hline Yes & $117(46.2)$ & $28(30.8)$ \\
\hline No & $124(49.0)$ & $62(68.1)$ \\
\hline Unknown & $12(4.7)$ & $1(1.1)$ \\
\hline \multicolumn{3}{|l|}{ Siblings, n (\%) } \\
\hline No & $29(11.5)$ & $6(6.6)$ \\
\hline One & $119(47.0)$ & $49(53.8)$ \\
\hline Two or more & $93(36.8)$ & $33(36.3)$ \\
\hline Unknown & $12(4.7)$ & $3(3.3)$ \\
\hline \multicolumn{3}{|l|}{ Siblings with VI, n (\%) } \\
\hline Yes & $41(16.2)$ & $21(23.1)$ \\
\hline No & $171(67.6)$ & $61(67.0)$ \\
\hline N/A (no/unknown siblings) & $41(16.2)$ & $9(9.9)$ \\
\hline
\end{tabular}


Table 2 Differences in distribution of responses over the response categories for the Dutch sample $(n=253)$ and the UK sample $(n=91)$

\begin{tabular}{|c|c|c|c|c|c|c|c|c|c|c|c|c|}
\hline \multirow[t]{2}{*}{ Item } & \multirow[t]{2}{*}{ Item content } & \multicolumn{4}{|c|}{$\begin{array}{l}\text { Distribution of } \\
\text { responding } \\
\text { population Dutch } \\
\text { sample (\%) over the } \\
\text { response options }{ }^{\mathrm{a}}\end{array}$} & \multirow[t]{2}{*}{$\begin{array}{l}\text { Missing } \\
\text { responses } \\
\text { Dutch } \\
\text { sample (\%) }\end{array}$} & \multicolumn{4}{|c|}{$\begin{array}{l}\text { Distribution } \\
\text { of responding } \\
\text { population UK } \\
\text { sample (\%) over } \\
\text { the response } \\
\text { options }^{\mathrm{a}}\end{array}$} & \multirow[t]{2}{*}{$\begin{array}{l}\text { Missing } \\
\text { responses } \\
\text { UK sample (\%) }\end{array}$} & \multirow[t]{2}{*}{$P$-value } \\
\hline & & 1 & 2 & 3 & 4 & & 1 & 2 & 3 & 4 & & \\
\hline FV_1 & Watching TV & 43.6 & 50.0 & 4.8 & 1.6 & 1.2 & 28.1 & 42.7 & 25.8 & 3.4 & 2.2 & $<0.001$ \\
\hline FV_2 & Playing video and computer games & 50.4 & 42.8 & 5.9 & 0.8 & 6.7 & 23.9 & 47.7 & 20.5 & 8.0 & 3.3 & $<0.001$ \\
\hline FV_3 & $\begin{array}{l}\text { Playing other games, e.g. board games or } \\
\text { card games }\end{array}$ & 35.4 & 53.6 & 10.5 & 0.4 & 6.3 & 21.3 & 34.8 & 38.2 & 5.6 & 2.2 & $<0.001$ \\
\hline FV_4 & Using the computer for homework & 35.8 & 56.2 & 7.3 & 0.7 & 45.8 & 26.1 & 52.3 & 17.0 & 4.5 & 3.3 & 0.020 \\
\hline FV_5 & Reading food packets, labels or recipes & 10.2 & 31.3 & 36.6 & 22.0 & 2.8 & 6.0 & 14.3 & 40.5 & 39.3 & 7.7 & 0.002 \\
\hline FV_6 & Doing household chores, e.g. washing up & 33.6 & 57.3 & 7.7 & 1.4 & 13.0 & 20.0 & 52.5 & 18.8 & 8.8 & 12.1 & $<0.001$ \\
\hline $\mathrm{FV} \_7$ & Telling the time on a wrist watch & 34.1 & 37.4 & 23.8 & 4.7 & 15.4 & 13.8 & 34.5 & 32.2 & 19.5 & 4.4 & $<0.001$ \\
\hline FV_8 & Telling the time on a wall clock & 26.8 & 45.2 & 17.6 & 10.5 & 5.5 & 11.2 & 28.1 & 30.3 & 30.3 & 2.2 & $<0.001$ \\
\hline FV_9 & Using the computer for lessons & 42.1 & 52.3 & 5.1 & 0.5 & 14.6 & 23.6 & 56.2 & 15.7 & 4.5 & 2.2 & $<0.001$ \\
\hline FV_10 & $\begin{array}{l}\text { Reading small print text books, worksheets } \\
\text { and exam papers }\end{array}$ & 11.6 & 28.9 & 35.5 & 24.0 & 4.3 & 3.4 & 13.6 & 38.6 & 44.3 & 3.3 & $<0.001$ \\
\hline FV_11 & $\begin{array}{l}\text { Reading enlarged text books, worksheets } \\
\text { and exam papers }\end{array}$ & 47.9 & 43.8 & 2.5 & 5.8 & 5.1 & 42.0 & 42.0 & 10.2 & 5.7 & 3.3 & 0.030 \\
\hline FV_12 & Drawing or painting & 32.5 & 56.3 & 8.3 & 2.9 & 5.1 & 30.3 & 33.7 & 31.5 & 4.5 & 2.2 & $<0.001$ \\
\hline FV_13 & Reading hand writing & 10.4 & 44.6 & 30.7 & 14.3 & 0.8 & 13.6 & 12.5 & 53.4 & 20.5 & 3.3 & $<0.001$ \\
\hline FV_14 & Seeing the board in the class & 25.0 & 46.0 & 19.4 & 9.7 & 2.0 & 8.2 & 23.5 & 35.3 & 32.9 & 6.6 & $<0.001$ \\
\hline FV_15 & Recognizing people, e.g. in school corridors & 32.4 & 48.6 & 15.0 & 4.0 & 0.0 & 15.9 & 33.0 & 33.0 & 18.2 & 3.3 & $<0.001$ \\
\hline FV_16 & Recognizing other people's facial expressions & 23.4 & 45.6 & 20.6 & 10.3 & 0.4 & 21.8 & 28.7 & 28.7 & 20.7 & 4.4 & 0.008 \\
\hline FV_17 & Finding friends in the playground & 21.6 & 43.6 & 30.8 & 4.0 & 1.2 & 8.0 & 28.4 & 36.4 & 27.3 & 3.3 & $<0.001$ \\
\hline FV_18 & Taking part in science classes & 23.7 & 60.4 & 13.7 & 2.2 & 45.1 & 23.3 & 51.1 & 20.0 & 5.6 & 1.1 & 0.261 \\
\hline FV_19 & Taking part in geography classes & 24.1 & 56.0 & 16.3 & 3.6 & 34.4 & 18.2 & 44.2 & 28.6 & 9.1 & 15.4 & 0.027 \\
\hline FV_20 & Taking part in math classes & 27.2 & 49.6 & 21.2 & 2.0 & 1.2 & 22.2 & 52.2 & 21.1 & 4.4 & 1.1 & 0.528 \\
\hline FV_21 & Taking part in PE & 39.3 & 50.4 & 9.4 & 0.8 & 3.6 & 20.7 & 35.6 & 35.6 & 8.0 & 4.4 & $<0.001$ \\
\hline FV_22 & Taking part in English/Dutch classes & 30.5 & 55.0 & 12.4 & 2.0 & 1.6 & 20.2 & 57.3 & 20.2 & 2.2 & 2.2 & 0.150 \\
\hline FV_23 & Keeping up with the teacher in lessons & 21.8 & 53.2 & 22.6 & 2.4 & 0.4 & 21.1 & 37.8 & 35.6 & 5.6 & 1.1 & 0.023 \\
\hline FV_24 & Keeping up with other students in class & 23.9 & 52.6 & 22.3 & 1.2 & 0.8 & 23.1 & 33.0 & 39.6 & 4.4 & 0.0 & 0.001 \\
\hline FV_25 & Getting around the school by yourself & 43.3 & 50.4 & 6.0 & 0.4 & 0.4 & 42.9 & 41.8 & 13.2 & 2.2 & 0.0 & 0.047 \\
\hline FV_26 & Getting around outdoors by yourself & 36.5 & 52.0 & 10.7 & 0.8 & 0.4 & 17.2 & 41.4 & 34.5 & 6.9 & 4.4 & $<0.001$ \\
\hline FV_27 & Reading signs and posters at stations or shops & 19.2 & 40.8 & 30.8 & 9.2 & 5.1 & 13.6 & 26.1 & 30.7 & 29.5 & 3.3 & $<0.001$ \\
\hline FV_28 & Getting around in crowds by yourself & 12.1 & 32.0 & 44.1 & 11.7 & 2.4 & 11.4 & 19.0 & 39.2 & 30.4 & 13.2 & 0.001 \\
\hline FV_29 & Seeing small moving objects, e.g. balls & 14.6 & 40.3 & 30.4 & 14.6 & 0.0 & 10.3 & 11.5 & 40.2 & 37.9 & 4.4 & $<0.001$ \\
\hline FV_30 & Seeing large moving objects, e.g. cars passing & 39.1 & 45.1 & 10.7 & 5.1 & 0.0 & 30.7 & 50.0 & 12.5 & 6.8 & 3.3 & 0.546 \\
\hline FV_31 & Using the escalators & 39.6 & 49.4 & 9.4 & 1.6 & 3.2 & 40.4 & 38.2 & 18.0 & 3.4 & 2.2 & 0.077 \\
\hline FV_32 & Playing team sports, e.g. football, without adaptations & 27.6 & 50.7 & 18.7 & 3.0 & 19.8 & 18.4 & 21.8 & 33.3 & 26.4 & 4.4 & $<0.001$ \\
\hline FV_33 & Watching films in the cinema & 40.5 & 51.4 & 7.3 & 0.9 & 13.0 & 34.8 & 40.4 & 19.1 & 5.6 & 2.2 & 0.001 \\
\hline FV_34 & Watching plays and shows in the theatre & 26.2 & 55.9 & 14.9 & 3.0 & 20.2 & 15.0 & 38.8 & 31.3 & 15.0 & 12.1 & $<0.001$ \\
\hline FV_35 & Reading price tags & 16.5 & 49.6 & 24.2 & 9.7 & 2.0 & 12.0 & 30.1 & 33.7 & 24.1 & 8.8 & $<0.001$ \\
\hline FV_36 & Finding correct money to pay & 22.6 & 55.7 & 20.0 & 1.7 & 9.1 & 22.4 & 40.0 & 25.9 & 11.8 & 6.6 & $<0.001$ \\
\hline
\end{tabular}

\footnotetext{
${ }^{a} 1$ : very easy; 2: easy; 3 : difficult; 4: very difficult/impossible
} 
Table 3 GRM item characteristics for the 24 item FVQ_CYP_NL $(n=253)$

\begin{tabular}{|c|c|c|c|c|c|c|c|}
\hline Item & Item content & Discrimination a & Threshold $\beta 1$ & Threshold $\beta 2$ & Item information & $x^{2}$ & $P$-value \\
\hline FV_1 & Watching TV & 1.32 & -0.26 & 2.49 & 2.45 & 8.17 & 0.52 \\
\hline FV_2 & Playing video and computer games & 1.19 & -0.02 & 2.56 & 2.12 & 13.04 & 0.22 \\
\hline FV_3 & Playing other games, e.g. board games or card games & 1.41 & -0.57 & 1.89 & 2.58 & 12.41 & 0.26 \\
\hline FV_8 & Telling the time on a wall clock & 1.74 & -0.84 & 0.85 & 3.06 & 13.45 & 0.20 \\
\hline FV_9 & Using the computer for lessons & 1.29 & -0.36 & 2.60 & 2.41 & 11.51 & 0.18 \\
\hline FV_10 & $\begin{array}{l}\text { Reading small print text books, worksheets and exam } \\
\text { papers }\end{array}$ & 1.11 & -2.26 & -0.43 & 1.76 & 11.69 & 0.39 \\
\hline FV_11 & $\begin{array}{l}\text { Reading enlarged text books, worksheets and exam } \\
\text { papers }\end{array}$ & 2.27 & -0.004 & 1.70 & 4.26 & 8.95 & 0.18 \\
\hline FV_13 & Reading hand writing & 1.22 & -2.24 & 0.24 & 2.17 & 9.03 & 0.53 \\
\hline FV_14 & Seeing the board in the class & 1.42 & -1.05 & 0.88 & 2.46 & 19.18 & 0.12 \\
\hline FV_15 & Recognizing people, e.g. in school corridors & 1.50 & -0.67 & 1.33 & 2.66 & 11.86 & 0.46 \\
\hline FV_16 & Recognizing other people's facial expressions & 1.67 & -1.03 & 0.74 & 2.96 & 19.43 & 0.05 \\
\hline FV_17 & Finding friends in the playground & 1.36 & -1.24 & 0.67 & 2.33 & 15.44 & 0.22 \\
\hline FV_24 & Keeping up with other students in class & 1.28 & -1.19 & 1.20 & 2.27 & 14.36 & 0.35 \\
\hline FV_25 & Getting around the school by yourself & 1.72 & -0.23 & 2.11 & 3.24 & 14.04 & 0.05 \\
\hline FV_26 & Getting around outdoors by yourself & 1.80 & -0.44 & 1.63 & 3.34 & 9.00 & 0.44 \\
\hline FV_27 & Reading signs and posters at stations or shops & 1.64 & -1.28 & 0.40 & 2.84 & 13.22 & 0.21 \\
\hline FV_28 & Getting around in crowds by yourself & 1.25 & -2.05 & -0.23 & 2.05 & 15.07 & 0.18 \\
\hline FV_29 & Seeing small moving objects, e.g. balls & 1.26 & -1.80 & 0.23 & 2.15 & 14.90 & 0.19 \\
\hline FV_30 & Seeing large moving objects, e.g. cars passing & 1.82 & -0.34 & 1.36 & 3.25 & 14.89 & 0.19 \\
\hline FV_31 & Using the escalators & 1.58 & -0.34 & 1.80 & 2.89 & 13.38 & 0.15 \\
\hline FV_32 & Playing team sports, e.g. football, without adaptations & 1.58 & -0.86 & 1.16 & 2.85 & 12.22 & 0.27 \\
\hline FV_33 & Watching films in the cinema & 1.90 & -0.37 & 1.77 & 3.59 & 8.50 & 0.29 \\
\hline FV_35 & Reading price tags & 1.61 & -1.45 & 0.64 & 2.93 & 15.53 & 0.11 \\
\hline FV_36 & Finding correct money to pay & 1.48 & -1.16 & 1.17 & 2.70 & 9.81 & 0.46 \\
\hline
\end{tabular}

inclusion criteria with respect to these variables in the Dutch sample.

\section{Item analyses}

Table 2 presents the distribution of responses over the response categories for the Dutch sample and the UK sample. The response option 'not applicable' was treated as a missing value. As such, four items in the Dutch sample had missing scores $>20 \%$ ("using the computer for homework", "taking part in science classes", "taking part in geography classes", and "watching plays and shows in the theatre") and these items were removed. None of the items had floor or ceiling effects, and in all items all four response categories were endorsed. However, infrequent endorsement of the response option 'very difficult or impossible' in almost all items in the Dutch sample motivated the collapsing of response options 'very difficult or impossible' and 'difficult'. There were no item pairs displaying high inter-item correlations $(>0.7)$. There were significant differences in the distribution of responses between the Dutch and the UK sample for all but five items. In general, the Dutch sample was more likely to opt for the response options 1 or 2 ('very easy' or 'easy') and less likely to opt for the response options 3 or 4 ('difficult' or 'very difficult/impossible') than the UK sample. Matching the Dutch sample on UK inclusion criteria (i.e. age $10-15$ years and VI logMAR $\geq 0.48 ; n=63$ for Dutch sample and $n=85$ for UK sample) did not influence these results.

\section{Calibration of the FVQ_CYP_NL}

The acceleration factor suggested a one-factor solution for the Dutch data. Principal components of the one-factor solution were all positive and moderate to large. Inspection of item and factor content gave no reason for multidimensional solutions. The first factor accounted for $33 \%$ of the variance, whereas the second factor accounted for $5 \%$ of the variance; thus, the ratio of explained variance by the first and second factor is 6.6, which is higher than the required minimum of 4 [45]. It was therefore concluded that the 


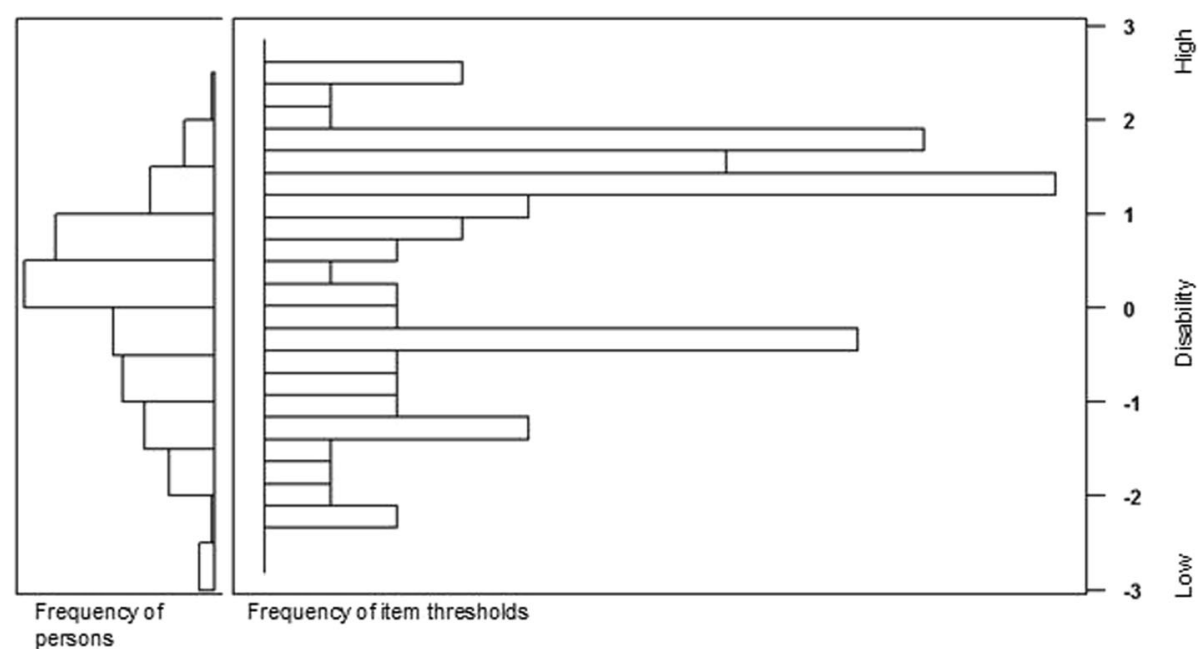

Fig. 1 Item-person map of the 24 item FVQ_CYP_NL

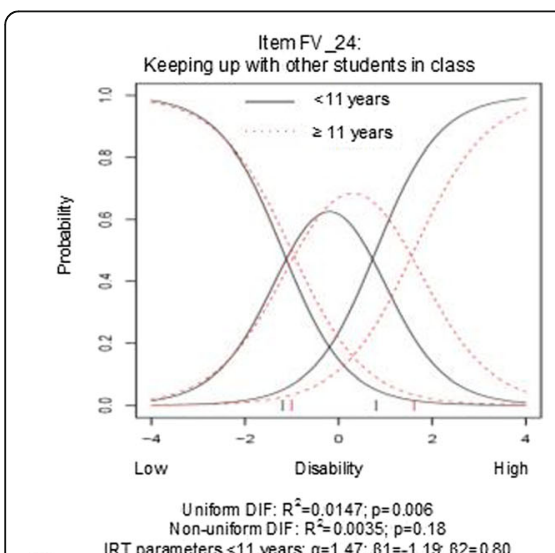

a IRT parameters $<11$ years: $\alpha=1.47 ; \beta 1=-1.19 ; \beta 2=0.80$

a IRT parameters $\geq 11$ years: $\alpha=1.28 ; \beta 1=-1.01 ; \beta 2=1.61$

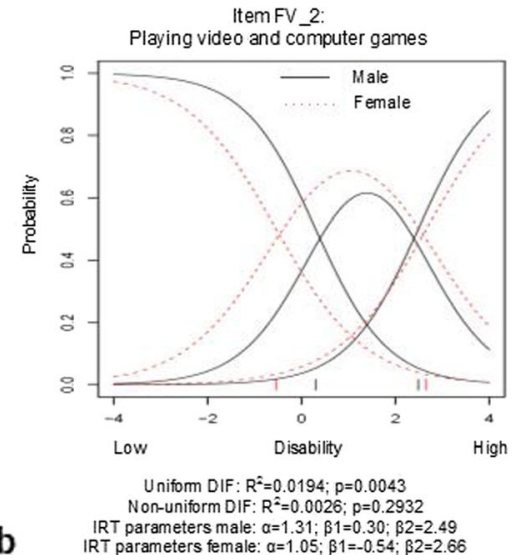

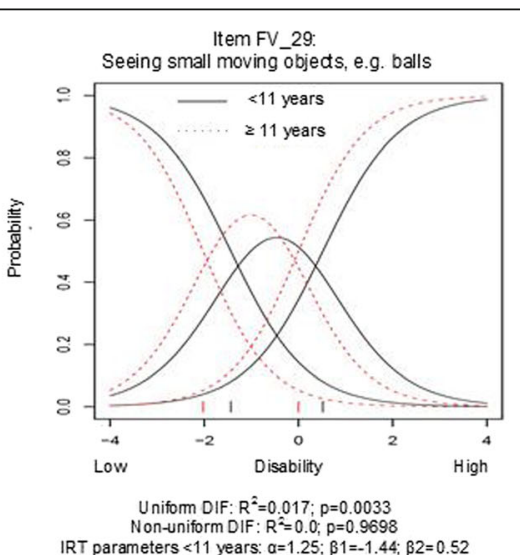

IRT parameters $<11$ years: $\alpha=1.25 ; \beta 1=-1.44 ; \beta 2=0.52$

Item FV_14:

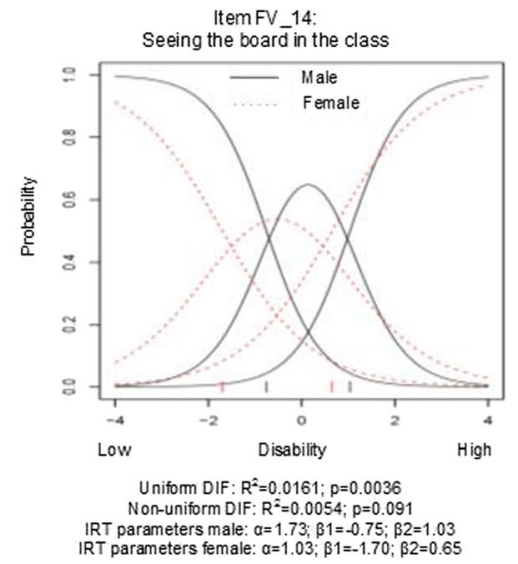

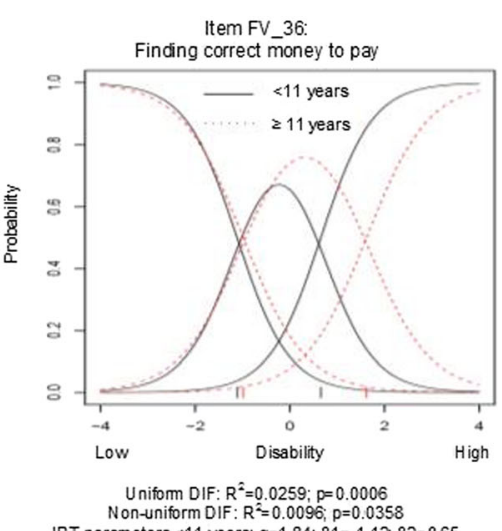

Unifom DIF: $R^{2}=0.0259 ; p=0.0006$ IRT parameters $<11$ years: $\alpha=1.84 ; \beta 1=-1.12 ; \beta 2=0.65$

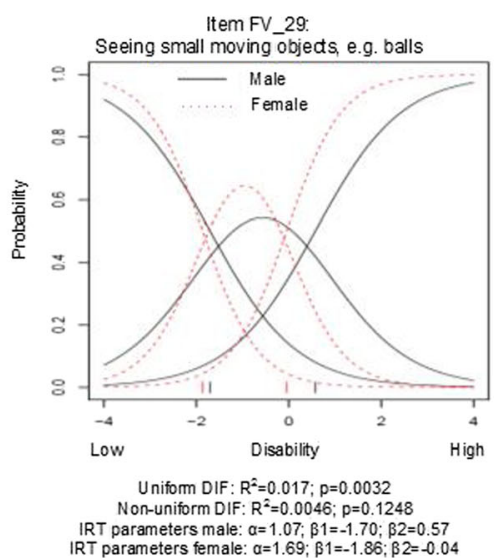

Fig. 2 Item response functions, McFadden's pseudo $R^{2}$ and $p$-values, and IRT parameters for items displaying DIF for age (a) and gender (b) $(n=253)$ 


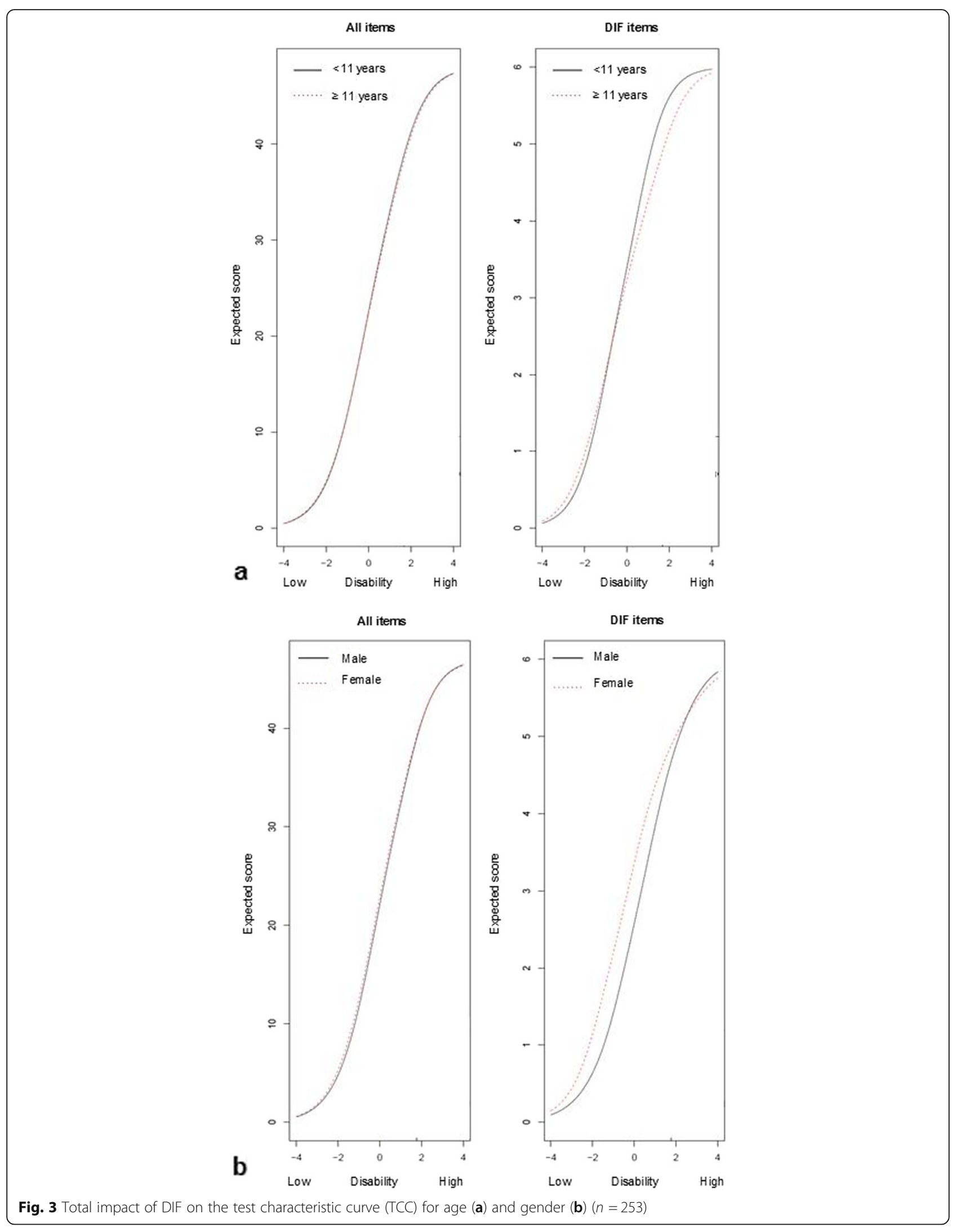


32 items stem from a unidimensional scale. Examination of the residual correlation matrix showed that one out of 496 item pairs (0.2\%) showed excess item covariation $(>0.25)$, violating the assumption of local independence ("keeping up with the teacher in lessons" - "keeping up with other students in class"). However, since the violation was not very severe (0.267), it was decided not to remove one of the items. Monotonicity analysis (piecewise assessment in sets of 16 items in order to retain samples after list wise deletion) showed that all items complied with monotonicity, and none of the items had a Loevinger $\mathrm{H}$ coefficient below 0.3 , indicating sufficient scalability.

Five items were removed after the first application of the GRM: "reading food packets, labels or recipes", "doing household chores, e.g. washing up", "telling the time on a wrist watch", "drawing or painting", and "keeping up with the teacher in lessons". These items were removed because they provided very little information (i.e. little precision/discrimination) and/or because they covered the same area on the disability trait as another item, but provided less information and/or provided information over a smaller range of the disability trait. Content validity, item relevance and similarities with other items were also considered. Three additional items were removed after the second fit of the GRM ("taking part in math classes", "taking part in physical education", and "taking part in Dutch language classes"), mainly because they still provided very little information.

The Likelihood Ratio test showed that the full GRM outperformed the polytomous Rasch model for the 24 items $(\mathrm{LRT}=40.0, p=0.015)$. The fit indices reflected adequate overall model fit of the 24 items to the GRM: RMSEA $=0.061$, SRMR $=0.062$, TLI $=0.965$, and CFI $=$ 0.968 . Table 3 summarizes GRM item parameters, information and fit statistics of the FVQ_CYP_NL. Item discrimination ranged from 1.11 to 2.27 . The item with the lowest discrimination was "reading small print text books, worksheets and exam papers", and the item with the highest discrimination was "reading enlarged text books, worksheets and exam papers". Item threshold parameters ranged from -2.26 to 2.60 . Item information ranged from 1.76 to 4.26 , and total information of the 24 items was 65.32. All items fitted the GRM at the $p<$ 0.01 level. Despite the fact that some items still provided little information, further item removal was considered unfavourable given the location of these items on the disability trait and for reasons of content validity. The item-person map shows that items are distributed almost entirely across the disability trait. The thetas of respondents adequately match the item thresholds, although there are no items for persons with low levels of disability (Fig. 1).
Differential item functioning and known-group validity After two iterations, analysis of DIF for age indicated three items with some level of DIF, which was all uniform (Fig. 2a). However, change in McFadden's $R^{2}$ was below $2 \%$ for two of the three items. For two items ("keeping up with other students in class" $\left(R^{2}=0.0147\right)$ and "finding correct money to pay" $\left.\left(\mathrm{R}^{2}=0.0259\right)\right)$, younger children were more likely to endorse higher response categories (signifying higher levels of difficulty) compared to older children. Item response functions suggest that uniform DIF was due to second category threshold values being smaller for the younger group than for the older group for both items. For one item ("seeing small moving objects, e.g. balls" $\left.\left(\mathrm{R}^{2}=0.017\right)\right)$, older children were more likely to endorse higher response categories. Here, the item response functions suggest that the category threshold values were both smaller for the older group than for the younger group. Analysis of DIF for gender also indicated three items with some level of DIF after three iterations (Fig. 2b), but change in McFadden's $\mathrm{R}^{2}$ was below 2\% ("playing video and computer games" $\left(R^{2}=0.0194\right)$, "seeing the board in the class" $\left(R^{2}=\right.$ 0.0161 ), and "seeing small moving objects, e.g. balls" $\left.\left(R^{2}=0.017\right)\right)$. According to $\chi^{2}$ tests, all items displayed uniform DIF. However, item response functions revealed non-uniform DIF, indicated by differences in slope parameters.

Figure 3a shows the total impact of DIF for age on the test characteristic curve (TCC), and Fig. 3b the total impact of DIF for gender. The TCC shows the relation between the total scores (y-axis) and thetas ( $\mathrm{x}$-axis). The left graphs show the impact on the test score for all items, whereas the right graphs show the impact of only those items with DIF. The curves show that the total score is the same for both age groups and genders, indicating minimal impact of DIF by age and gender.

Known-group validity was established for groups that differ on level of VI and gender. Those with severe VI/ blindness had significantly higher thetas than those with moderate VI and mild VI $(\mathrm{p}=0.002$ and $p<0.001$ respectively), indicating that they experienced more disability and the FVQ_CYP_NL was able to discriminate them. Females had significantly higher thetas than males $(p=0.008)$, and no significant differences were found in thetas between those with and without other impairments.

\section{Discussion}

This study reports the cross-cultural adaptation of the original UK version of the FVQ_CYP into Dutch and its important psychometric properties. The FVQ_CYP is a PROM which measures functional vision of children and adolescents with VI [18]. Following standardized translation processes, the original English instrument translated well into Dutch resulting in a new Dutch version of the 
questionnaire - the FVQ_CYP_NL. However, the crosscultural validation in the Dutch population using the measurement model specifications and assumptions used in the original UK study was not straightforward. Since some adaptations needed to be made to achieve model fit of the Dutch version, it can be argued whether the FVQ_CYP_NL still measures the same construct as the original UK FVQ_CYP. However, both versions proved to be unidimensional scales with a broad coverage of items measuring children's self-assessed ability to endorse vision-dependent tasks. The FVQ_CYP_NL has high measurement precision, is targeted adequately to the abilities of children and adolescents aged 7-17 years with different levels of VI, and can discriminate between these levels.

We originally planned to perform 'strict' cross-cultural validation of the FVQ_CY_NL by applying the same criteria for item analyses as used in the validation study of the UK questionnaire [18], using the RSM, and conducting DIF analysis for country. This would have allowed direct cross-cultural comparisons in future studies as well as pooling the data from the two countries for instance in the context of trials of new therapies or interventions.

Interestingly, we found a number of differences in the psychometric performance of the instrument versions of the two countries. There were differences in the distribution of missing responses and response patterns between the Dutch data and the UK data. Some items had high missing responses in the Netherlands, but not in the UK, and Dutch children were less likely to opt the response category 'very difficult/impossible'. There are a number of possible reasons for these differences. Firstly, the difference in instrument performance between countries may have been driven by differences in the population due to the broader age range and less restrictions in degree of vision impairment in the Dutch sample. There were also differences in the presence of comorbidity between the samples. Matching the samples did not improve the results. Secondly, differences might have been influenced by different modes of administration. Data in the original UK study had been collected as self-report and self-completion with questionnaires returned by post [18], whereas in the Netherlands data was collected using face-to-face interviews via home visits. Face-toface interviews are known to be more prone to social desirability bias and yes-saying bias, while respondents are less willing to disclose sensitive information [46]. Thirdly, the FVQ_CYP UK version was developed within a specific population which drove the questionnaire content, including semi-structured and cognitive interviews with children and adolescents to develop and shape the instrument items and formats. Thus, the FVQ_CYP may more accurately capture the UK children's functional vision because the content is more relevant to them both with respect to age and level of acuity: interviewing Dutch children to develop a similar instrument de novo may have resulted in a different set of items. Despite the mismatch between the Dutch population and the intended target population of the FVQ_CYP with respect to age and level of vision impairment, we decided to use the FVQ_CYP because it currently is the most robust instrument to measure functional vision in children.

Besides the differences in psychometric performance, there was non-invariance at the model level; the RSM did not fit the Dutch data, whereas fit for the UK data was satisfactory. The RSM assumes that the discrimination parameter (i.e. the slope) is equal across all items (and therefore this model belongs to the Rasch family), and that the thresholds for each category response are also equal across items [40]. These assumptions make the RSM among the more restrictive IRT models. However, the RSM can tolerate smaller sample sizes than the commonly used GRM, which has fewer assumptions and is more flexible [40]. The sample sizes of both the UK data and the Dutch data were modest and therefore rather limited for the advanced analyses conducted in this study [24, 47]; furthermore, the difference in sample size between the Dutch data and UK data might have contributed to the non-invariance at the model level, as any model fit is contingent upon sample size. Besides unsatisfactory overall fit of the RSM to the Dutch data, various tests for item fit indicated misfit of items to the model. After iteratively removing those items with most misfit, the goodness-of-fit test was suggestive for satisfactory model fit of the RSM. However, by then only 12 items were maintained in the FVQ_CYP_NL, which was considered undesirable because of the threat to face and content validity. Matching of the Dutch sample to UK inclusion criteria led to more violations to IRT assumptions. Model fit improved, but 11 items were excluded in the analysis because of inappropriate response patterns, and tests for item fit still indicated items with misfit.

Measurement invariance implies that the association between test scores and latent traits of persons is unconditional on group affiliation or time of measurement [48]. The non-invariance at the model level already implied that there would be DIF for country or noninvariance at item level as well. The assumption of measurement invariance rarely holds, especially when parameters are expected to be exactly the same across groups. But even when applying less strict criteria, the occurrence of measurement invariance is often ignored, and populations are compared even though there is no psychometric basis for it, thereby introducing potential bias [48]. Most studies only report the results of DIF analyses in assessing cross-cultural validity, not taking into account the measurement model specifications and 
assumptions used in the original validation study. We chose not to ignore measurement invariance, and used a different IRT model to investigate the FVQ_CYP_NL and compare it to the original FVQ_CYP. As such, the two instruments were not calibrated on the same scale and, consequently, item parameters of the original UK instrument and the FVQ_CYP_NL are not comparable. In addition, changes were made in the number of items of the FVQ_CYP_NL, and in response options. Therefore, someone with the same true theta on the disability trait who completes the FVQ_CYP_NL will have a different score when completing the original FVQ_CYP.

Application of the GRM resulted in the identification of eight items that contributed very little information or covered the same area on the disability trait as another item while providing less information, and therefore these were removed. Together with the four items that had too many missing responses, this resulted in an instrument containing 24 items. Some of the items which were deleted might have been less relevant for younger children (i.e. "using the computer for homework", "doing household chores, e.g. washing up", and "reading food packets, labels or recipes"). The item "telling the time on a wrist watch" might have been superseded by modern technology, e.g. the use of smartphones. This might even be true for younger children, as $68 \%$ of the 10 -year olds in the Netherlands had a smartphone in 2017 [49]. The large variability of mandatory classes in the Dutch school system might have caused that items on individual classes were less relevant to Dutch children, contributing to the high number of missing values. For instance, science classes en geography are only mandatory for older children at some point, but the age at which these classes are mandatory is also dependent on school level. The item "drawing or painting" might have been less relevant for older children, as art is an elective class at several educational levels and ages in the Dutch school system. Furthermore, it was hypothesized that the influence of impaired vision on school performance is probably better captured by items such as reading text books, seeing the board and keeping up with other students, than by items about individual classes, for which endorsement might be more driven by other factors, such as individual talents or pedagogical methods. This hypothesis supported the removal of the items "taking part in math classes", "taking part in physical education", and "taking part in Dutch language classes" and the other class-specific items mentioned above.

The item thresholds of the final instrument reflected a good coverage across the disability trait. The FVQ_CYP_ NL seemed better targeted to children and adolescents with higher thetas at the disability trait, and there might be a need for more difficult items. However, this was also expected, because the FVQ_CYP was originally developed with and for children with more severe visual impairment than the Dutch sample. This study shows that, with appropriate modification, it is also possible to administer the questionnaire to children and adolescents outside the original $10-15$ years age interval, and to children and adolescents with less severe visual impairment. This was already anticipated by the authors of the original FVQ_CYP, who are currently completing development and an additional assessment of psychometric properties of age-appropriate versions applicable to a wider age range [18].

The DIF analyses identified three items with uniform DIF for age and three items (one overlapping) with nonuniform DIF for gender (although results of $x^{2}$ tests point towards uniform DIF). However, DIF had minimal impact on the total score, and therefore we concluded that item differences for age groups and gender are negligible, and removing these items was not necessary. Although one could argue that the impact of DIF on the total test score is most important, we believe it is also important to mention DIF per item. When for example selecting items for a short form or computer adaptive test (CAT), it is important to know which items display DIF, and omitting these items in the short form or CAT would be preferred.

Infrequent endorsement of the fourth response category motivated collapsing the third and fourth category. However, adding the 'not applicable' response option might have caused attrition in the data, because children might have opted for the 'not applicable' category where they also could have opted for 'very difficult/impossible'. This was also speculated to be the case in the validation of the original instrument in the UK, and with frequent endorsement of the 'not applicable' option resulting in a high proportion of missing data, the authors subsequently decided to remove 'not applicable' as a response option from the instrument [18]. However, because of the wider age range in the Dutch sample, the response option 'not applicable' was warranted in the FVQ_CYP_ $\mathrm{NL}$, as children aged for example 7 years do not have certain classes in school or receive homework. The deletion of items ensured that the items in the final 24 item version of the FVQ_CYP_NL are probably applicable to the entire age range (e.g. 7-17 years), and therefore the response option 'not applicable' could be deleted again, in order to prevent entanglement with the fourth response category. Consequently, it should be tested whether the fourth response category can exist independently, or whether collapsing it with the third category is still necessary. Furthermore, 10 participants commented that the distance between the second and third category (i.e. 'easy' and 'difficult') was too large, and an answer option in between is necessary. In a large share of the participants, the interviewers also noted that children were often in doubt on whether to opt for 'easy' 
or 'difficult' in at least some items, and therefore addition of the response option 'little difficult' would be desirable.

\section{Conclusions}

In conclusion, non-invariance at the model level, small sample sizes, and differences in population characteristics and distribution of responses posed challenges to the standard cross-cultural validation process. However, although this imposes limitations to direct comparability of the FVQ-CYP between the Netherlands and UK, by using a GRM, we have established validity of the FVQ CYP_NL as a stand-alone instrument for use in the Netherlands (thus the FVQ_CYP UK version served as the building block). The Dutch adapted FVQ_CYP - the FVQ_CYP_NL - is a unidimensional scale with high measurement precision and broad coverage of items measuring children's functional vision. Deletion of items ensured that only those items most applicable to the Dutch setting and providing high information were included in the final questionnaire. This study provides detailed information on item parameters, and shows that the FVQ_CYP_NL is targeted adequately to the abilities of children and adolescents aged 7-17 with different levels of VI. In its current form the FVQ_CYP_NL is a short, easy to administer instrument, with sound psychometric properties, which can be used to assess the selfreported level of difficulty in performing vision-dependent activities in children and adolescents with visual impairment. However, further evaluation of psychometric properties such as the application and functioning of the recommended response categories, construct validity, test-retest reliability, and responsiveness is necessary.

Our study has implications for cross-cultural use of instruments in general. Given the scarcity of measures for children and adolescents in ophthalmology and the challenges in developing instruments de novo with heterogeneous and numerically small clinical populations, there is a value in using well developed instruments and adapting them cross-culturally. However, care must be taken that rigorous, standard cross-cultural validation processes are followed. Even when instruments are invariant at model or item level, it is possible to have language versions of an instrument that are reliable and valid for use in each country but differ extensively in wording or are even comprised of different items from item banks, that demonstrate identical response functions, facilitating cross-cultural use [50]. Our findings highlight that instruments cannot simply be taken and translated into another language whilst expecting that the underlying psychometric assumptions will remain across different cultures. We argue that when performing cross-cultural validations, researchers should assess invariance at both model level and item level (i.e. DIF analyses), and confirm that language versions function similarly in different countries. If this is not the case, considering the original instrument as the building blocks and assessing psychometric properties of the new language version using more liberal assumptions is recommended.

\begin{abstract}
Abbreviations
CFI: Comparative fit index; CRC: Category response curve; DIF: Differential item functioning; FVQ_CYP: Functional Vision Questionnaire for Children and Young People; FVQ_CYP_NL: Dutch version of the Functional Vision Questionnaire for Children and Young People; GRM: Graded response model; IIC: Item information curve; IRT: Item response theory; PAI-CY: Participation and Activity Inventory for Children and Youth; PCA: Principal component analysis; PROM: Patient-reported outcome measure; RMSEA: Root mean square error of approximation; RSM: Rating scale model; SRMR: Standardized root mean square residual; TCC: Test characteristic curve; TLI: Tucker-Lewis index; UK: United Kingdom; VI: Visual impairment; WHO: World Health Organisation
\end{abstract}

\section{Acknowledgements}

We would like to thank all participating children.

\section{Authors' contributions}

$E E, V T, R v N, G v R$ \& JR were involved in funding acquisition; EE, VT, GVR, JR, \& RVN conceptualized and designed the study; EE \& VT collected the data; $E$, VT \& CP carried out the data analyses; EE, VT, CP \& RvN were involved in interpretation of the data and results; EE \& VT drafted the manuscript; JR, RvN, CP \& GvR revised and approved the manuscript. All authors read and approved the final manuscript.

\section{Funding}

This study was funded by a fellowship of Royal Dutch Visio. A travel grant for this study was provided by the Quality of Care programme of the Amsterdam Public Health research institute. The sponsors had no role in the design, conduct or outcomes of this study.

The initial study developing and validating the FVQ_CYP in the UK was funded by a Fight for Sight Project Grant (2014). Further support was received from the following sources: Guide Dogs for the Blind Association, National Institute of Health Research (NIHR) Biomedical Research Centre at Moorfields Eye Hospital NHS Foundation Trust and University College London Institute of Ophthalmology, and NIHR Central and East London Comprehensive Research Network. The study was undertaken at University College London Institute of Child Health/Great Ormond Street Hospital and Moorfields Eye Hospital/at University College London Institute of Ophthalmology, both of which receive a proportion of funding from the Department of Health's NIHR Biomedical Research Center's funding scheme. Members of the team are supported by the Ulverscroft Foundation. The FVQ_CYP is available on request from Professor Rahi. Copyright statement: The FVQ_CYP should not be reproduced or modified without Professor Rahi's permission. Copyright@ 2013 University College London (UCL) Institute of Child Health.

\section{Availability of data and materials \\ The datasets used and/or analysed during the current study are available from the corresponding author on reasonable request.}

\section{Ethics approval and consent to participate}

The study protocol was approved by the Medical Ethical Committee of the VU University Medical Centre, Amsterdam, the Netherlands. All procedures performed in studies involving human participants were in accordance with the ethical standards of the institutional and/or national research committee and with the 1964 Helsinki declaration and its later amendments or comparable ethical standards. Written informed consent was obtained from all Dutch participants, i.e. from parents of all children, and from children and adolescents aged 13 years and older. Secondary analysis of the existing anonymised UK FVQ_CYP dataset did not require ethics approval. The data were drawn from the original development and psychometric study which 
involved individual consent to participation and was approved by the National Health Service Research Ethics Committee for UCL Institute of Child Health and Great Ormond Street Hospital, United Kingdom, and followed the tenets of the Declaration of Helsinki.

\section{Consent for publication}

Not applicable.

\section{Competing interests}

Dr. Peeters and Dr. van Nispen are editorial board members of BMC Medical Research Methodology. Professor Rahi is a National Institute for Health Research (NIHR) Senior Investigator. The views expressed in this article are those of the author(s) and not necessarily those of the NHS, the NIHR, or the Department of Health. The remaining authors have no competing interests.

\section{Author details}

${ }^{1}$ Department of Ophthalmology, Amsterdam UMC, Vrije Universiteit Amsterdam, the Amsterdam Public Health research institute, Amsterdam, the Netherlands. ${ }^{2}$ School of Human Sciences, University of Greenwich, London, UK. ${ }^{3}$ Life Course Epidemiology and Biostatistics Section, Population, Policy and Practice Programme, UCL Great Ormond Street Institute of Child Health, London, UK. ${ }^{4}$ Great Ormond Street Hospital for Children NHS Foundation Trust, London, UK. ${ }^{5}$ Department of Epidemiology \& Biostatistics, Amsterdam UMC, Vrije Universiteit Amsterdam, the Amsterdam Public Health research institute, Amsterdam, the Netherlands. ${ }^{6}$ Department of Ophthalmology, Elkerliek Hospital, Helmond, the Netherlands. ${ }^{7}$ Ulverscroft Vision Research Group, London, UK. ${ }^{8}$ National Institute for Health Research (NIHR) Biomedical Research Centre at Moorfields Eye Hospital NHS Foundation Trust and UCL Institute of Ophthalmology, London, UK.

\section{Received: 26 July 2018 Accepted: 21 November 2019}

\section{Published online: 03 December 2019}

\section{References}

1. Black N, Jenkinson C. Measuring patients' experiences and outcomes. BMJ. 2009;339:b2495.

2. Smith SC, Cano S, Lamping DL, Staniszewska S, Browne J, Lewsey J et al. Patient-reported outcome measures (PROMs) for routine use in treatment Centres: recommendations based on a review of the scientific evidence. Final report to the Department of Health. 2005.

3. Black N. Patient reported outcome measures could help transform healthcare. BMJ. 2013:346:f167.

4. Breitscheidel L, Stamenitis S. Using patient-reported outcome assessments in clinical practice and their importance in risk management. J Med Econ. 2009;12(3):180-1.

5. Greenhalgh J. The applications of PROs in clinical practice: what are they, do they work, and why? Qual Life Res. 2009;18(1):115-23.

6. Frost NA, Sparrow JM, Durant JS, Donovan JL, Peters TJ, Brookes ST. Development of a questionnaire for measurement of vision-related quality of life. Ophthalmic Epidemiol. 1998:5(4):185-210.

7. Hassell JB, Weih LM, Keeffe JE. A measure of handicap for low vision rehabilitation: the impact of vision impairment profile. Clin Exp Ophthalmol. 2000;28(3):156-61.

8. Mangione CM, Lee PP, Gutierrez PR, Spritzer K, Berry S, Hays RD, et al. Development of the 25-item National eye Institute visual function questionnaire. Arch Ophthalmol. 2001;119(7):1050-8.

9. Horowitz A, Reinhardt JP. Development of the adaptation to age-related vision loss scale. J Visual Impair Blin. 1998;92(1):30-41.

10. Wolffsohn JS, Cochrane AL. Design of the low vision quality-of-life questionnaire (LVQOL) and measuring the outcome of low-vision rehabilitation. Am J Ophthalmol. 2000;130(6):793-802. https://doi.org/10. 1016/S0002-9394(00)00610-3.

11. Steinberg EP, Tielsch JM, Schein OD, Javitt JC, Sharkey P, Cassard SD, et al. The Vf-14 - an Index of Functional Impairment in Patients with Cataract. Arch Ophthalmol-Chic. 1994;112(5):630-8. https://doi.org/10.1001/archopht. 1994.01090170074026

12. Lundstrom $M$, Roos $P$, Jensen $S$, Fregell $G$. Catquest questionnaire for use in cataract surgery care: Description, validity, and reliability. J Cataract Refr Surg. 1997;23(8):1226-36. https://doi.org/10.1016/S0886-3350(97)80321-5.
13. Gothwal VK, Lovie-Kitchin JE, Nutheti R. The development of the LV Prasadfunctional vision questionnaire: a measure of functional vision performance of visually impaired children. Invest Ophthalmol Vis Sci. 2003;44(9):4131-9.

14. Gothwal VK, Sumalini R, Bharani S, Reddy SP, Bagga DK. The second version of the L. V. Prasad-functional vision questionnaire. Optom Vis Sci. 2012; 89(11):1601-10. https://doi.org/10.1097/OPX.0b013e31826ca291.

15. Huang J, Khadka J, Gao R, Zhang S, Dong W, Bao F, et al. Validation of an instrument to assess visual ability in children with visual impairment in China. Brit J Ophthalmol. 2016. https://doi.org/10.1136/bjophthalmol-2016308866.

16. Tunay ZÖ, Çalişkan D, Öztuna D, Idil A. Validation and reliability of the Cardiff Visual Ability Questionnaire for Children using Rasch analysis in a Turkish population. Brit J Ophthalmol. 2015. https://doi.org/10.1136/ bjophthalmol-2015-307122

17. Khadka J, Ryan B, Margrain TH, Court H, Woodhouse JM. Development of the 25-item Cardiff visual ability questionnaire for children (CVAQC). Br J Ophthalmol. 2010;94(6):730-5. https://doi.org/10.1136/bjo.2009.171181.

18. Tadic V, Cooper A, Cumberland P, Lewando-Hundt G, Rahi JS. Vision-related quality of life $\mathrm{G}$. development of the functional vision questionnaire for children and young people with visual impairment: the FVQ_CYP. Ophthalmology. 2013; 120(12):2725-32. https://doi.org/10.1016/j.ophtha.2013.07.055.

19. Elsman EBM, van Nispen RMA, van Rens GHMB. Feasibility of the Participation and Activity Inventory for Children and Youth (PAI-CY) and Young Adults (PAI-YA) with a visual impairment: a pilot study. Health Qual Life Out. 2017;15:98. https://doi.org/10.1186/s12955-017-0677-X.

20. Beaton DE, Bombardier C, Guillemin F, Ferraz MB. Guidelines for the process of cross-cultural adaptation of self-report measures. Spine. 2000;25(24):3186-91. https://doi.org/10.1097/00007632-200012150-00014.

21. WHO. International Statistical Classification of Diseases and Related Health Problems 10th Revision. Version 2010. Chapter VII, H54: visual impairment including blindness. Geneva: World Health Organization; 2010.

22. R: A language and environment for statistical computing. Vienna. R Core Team R Foundation for Statistical Computing; 2017. https://www.R-project.org/:

23. IBM Corp N. IBM SPSS Statistics for Windows, Version 22.0. Armonk, NY: IBM Corp; 2013.

24. Edelen $\mathrm{MO}$, Reeve BB. Applying item response theory (IRT) modeling to questionnaire development, evaluation, and refinement. Qual Life Res. 2007; 16(Suppl 1):5-18. https://doi.org/10.1007/s111136-007-9198-0.

25. Reeve $\mathrm{BB}$, Hays RD, Chang $\mathrm{CH}$, Perfetto EM. Applying item response theory to enhance health outcomes assessment. Qual Life Res. 2007:16:1-3. https://doi.org/10.1007/s11136-007-9220-6.

26. Raîche G, Walls TA, Magis D, Riopel M, Blais J-G. Non-graphical solutions for Cattell's scree test. Methodology. 2013;9(1):23-29. https://doi.org/10.1027/ 1614-2241/a000051.

27. Pilkonis PA, Choi SW, Reise SP, Stover AM, Riley WT, Cella D, et al. Item banks for measuring emotional distress from the patient-reported outcomes measurement information system (PROMIS(R)): depression, anxiety, and anger. Assessment. 2011;18(3):263-83. https://doi.org/10.1177/ 1073191111411667.

28. Loevinger J. The technic of homogeneous tests compared with some aspects of scale analysis and factor analysis. Psychol Bull. 1948;45(6):507-29.

29. Meijer RR, Baneke JJ. Analyzing psychopathology items: a case for nonparametric item response theory modeling. Psychol Methods. 2004:9(3): 354-68. https://doi.org/10.1037/1082-989X.9.3.354.

30. Sijtsma K, Meijer RR, van der Ark LA. Mokken scale analysis as time goes by an update for scaling practitioners. Pers Indiv Differ. 2011;50(1):31-7. https://doi.org/10.1016/j.paid.2010.08.016.

31. Mair P, Hatzinger R. Extended Rasch modeling: the eRm package for the application of IRT models in R. J Stat Softw. 2007;20(9):1-20.

32. Samejima F. Estimation of Latent Ability Using a Response Pattern of Graded Scores. Psychometrika. 1969;34(4p2):1 \&.

33. Samejima F. Graded response model. In: Van der Linden W, Hambleton RK, editors. Handbook of modern item response theory. New York: Springer 1997. p. $85-100$.

34. Rizopoulos D. Itm: An R package for latent variable modeling and item response theory analyses. J Stat Softw. 2006;17(5):1-25.

35. Bond TG, Fox CM. Applying the Rasch model - fundamental measurement in the human sciences (2ed.). Mahwah: Lawrence Erlbaum Associates Publishers; 2007

36. Chalmers RP. Mirt: a multidimensional item response theory package for the R environment. J Stat Softw. 2012;48(6):1-29. 
37. Hu LT, Bentler PM. Cutoff criteria for fit indexes in covariance structure analysis: conventional criteria versus new alternatives. Struct Equ Modeling. 1999;6(1):1-55. https://doi.org/10.1080/10705519909540118.

38. Bock RD. Estimating item parameters and latent ability when responses are scored in two or more nominal categories. Psychometrika. 1972;37(1):29-51.

39. Yen WM. Using simulation results to choose a latent trait model. Appl Psychol Meas. 1981;5(2):245-62

40. Nguyen TH, Han HR, Kim MT, Chan KS. An introduction to item response theory for patient-reported outcome measurement. Patient. 2014;7(1):23-35. https://doi.org/10.1007/s40271-013-0041-0

41. Irribarra TD, Freund R. Wright Map: IRT item-person map with ConQuest integration; 2014.

42. De Vet HCW, Terwee CB, Mokkink LB, Knol DL. Measurement in Medicine: a practical guide. New York: Cambridge University Press; 2011.

43. Choi SW, Gibbons LE, Crane PK. Lordif: an R package for detecting differential item functioning using iterative hybrid ordinal logistic regression/item response theory and Monte Carlo simulations. J Stat Softw. 2011;39(8):1.

44. Choi SW, Gibbons LE, Crane PK. Lordif: an R package fo rDetecting differential item functioning using iterative hybrid ordinal logistic regression/item response theory and Monte Carlo simulations. J Stat Softw. 2011:39(8):1-30.

45. Reeve BB, Hays RD, Bjorner JB, Cook KF, Crane PK, Teresi JA, et al. Psychometric evaluation and calibration of health-related quality of life item banks: plans for the patient-reported outcomes measurement information system (PROMIS). Med Care. 2007;45(5):S22-31.

46. Bowling A. Mode of questionnaire administration can have serious effects on data quality. J Public Health (Oxf). 2005;27(3):281-91. https://doi.org/10. 1093/pubmed/fdio31.

47. Tsutakawa RK, Johnson JC. The Effect of Uncertainty of Item ParameterEstimation on Ability Estimates. Psychometrika. 1990;55(2):371-90. https://doi.org/10.1007/Bf02295293.

48. Van De Schoot R, Schmidt P, De Beuckelaer A, Lek K, ZondervanZwijnenburg M. Measurement invariance. Front Psychol. 2015;6:1064.

49. Kennisnet. Monitor Youth and Media 2017 [Monitor Jeugd en Media 2017]. Zoetermeer: Kennisnet; 2017.

50. Kucukdeveci AA, Sahin H, Ataman S, Griffiths B, Tennant A. Issues in crosscultural validity: example from the adaptation, reliability, and validity testing of a Turkish version of the Stanford health assessment questionnaire. Arthrit Rheum-Arthr. 2004;51(1):14-9. https://doi.org/10.1002/art.20091.

\section{Publisher's Note}

Springer Nature remains neutral with regard to jurisdictional claims in published maps and institutional affiliations.

Ready to submit your research? Choose BMC and benefit from:

- fast, convenient online submission

- thorough peer review by experienced researchers in your field

- rapid publication on acceptance

- support for research data, including large and complex data types

- gold Open Access which fosters wider collaboration and increased citations

- maximum visibility for your research: over $100 \mathrm{M}$ website views per year

At BMC, research is always in progress.

Learn more biomedcentral.com/submissions 